NASA/TM-2004-213329

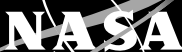

\title{
An Overview of Electric Propulsion Activities at NASA
}

John W. Dunning, Jr., John A. Hamley, Robert S. Jankovsky, and Steven R. Oleson Glenn Research Center, Cleveland, Ohio 
Since its founding, NASA has been dedicated to the advancement of aeronautics and space science. The NASA Scientific and Technical Information (STI) Program Office plays a key part in helping NASA maintain this important role.

The NASA STI Program Office is operated by Langley Research Center, the Lead Center for NASA's scientific and technical information. The NASA STI Program Office provides access to the NASA STI Database, the largest collection of aeronautical and space science STI in the world. The Program Office is also NASA's institutional mechanism for disseminating the results of its research and development activities. These results are published by NASA in the NASA STI Report Series, which includes the following report types:

- TECHNICAL PUBLICATION. Reports of completed research or a major significant phase of research that present the results of NASA programs and include extensive data or theoretical analysis. Includes compilations of significant scientific and technical data and information deemed to be of continuing reference value. NASA's counterpart of peerreviewed formal professional papers but has less stringent limitations on manuscript length and extent of graphic presentations.

- TECHNICAL MEMORANDUM. Scientific and technical findings that are preliminary or of specialized interest, e.g., quick release reports, working papers, and bibliographies that contain minimal annotation. Does not contain extensive analysis.

- CONTRACTOR REPORT. Scientific and technical findings by NASA-sponsored contractors and grantees.
- CONFERENCE PUBLICATION. Collected papers from scientific and technical conferences, symposia, seminars, or other meetings sponsored or cosponsored by NASA.

- SPECIAL PUBLICATION. Scientific, technical, or historical information from NASA programs, projects, and missions, often concerned with subjects having substantial public interest.

- TECHNICAL TRANSLATION. Englishlanguage translations of foreign scientific and technical material pertinent to NASA's mission.

Specialized services that complement the STI Program Office's diverse offerings include creating custom thesauri, building customized databases, organizing and publishing research results ... even providing videos.

For more information about the NASA STI Program Office, see the following:

- Access the NASA STI Program Home Page at http://www.sti.nasa.gov

- E-mail your question via the Internet to help@sti.nasa.gov

- Fax your question to the NASA Access Help Desk at 301-621-0134

- Telephone the NASA Access Help Desk at 301-621-0390

- Write to:

NASA Access Help Desk

NASA Center for AeroSpace Information 7121 Standard Drive

Hanover, MD 21076 
NASA/TM-2004-213329

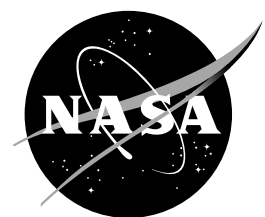

\section{An Overview of Electric Propulsion Activities at NASA}

John W. Dunning, Jr., John A. Hamley, Robert S. Jankovsky, and Steven R. Oleson Glenn Research Center, Cleveland, Ohio

Prepared for the 40th Joint Propulsion Conference and Exhibit cosponsored by the AIAA, ASME, SAE, and ASEE Fort Lauderdale, Florida, July 11-14, 2004

National Aeronautics and Space Administration

Glenn Research Center 
Available from

NASA Center for Aerospace Information 7121 Standard Drive

Hanover, MD 21076
National Technical Information Service 5285 Port Royal Road Springfield, VA 22100

Available electronically at http://gltrs.grc.nasa.gov 


\title{
An Overview of Electric Propulsion Activities at NASA
}

\author{
John W. Dunning, Jr., John A. Hamley, Robert S. Jankovsky, and Steven R. Oleson \\ National Aeronautics and Space Administration \\ Glenn Research Center \\ Cleveland, Ohio 44135
}

\begin{abstract}
This paper provides an overview of NASA's activities in the area of electric propulsion with an emphasis on project directions, recent progress, and a view of future project directions. The goals of the electric propulsion programs are to develop key technologies to enable new and ambitious science missions and to transfer these technologies to industry. Activities include the development of gridded ion thruster technology, Hall thruster technology, pulsed plasma thruster technology, and very high power electric propulsion technology, as well as systems technology that supports practical implementation of these advanced concepts. The performance of clusters of ion and Hall thrusters is being revisited. Mission analyses, based on science requirements and preliminary mission specifications, guide the technology projects and introduce mission planners to new capabilities. Significant in-house activity, with strong industrial/academia participation via contracts and grants, is maintained to address these development efforts. NASA has initiated a program covering nuclear powered spacecraft that includes both reactor and radioisotope power sources. This has provided an impetus to investigate higher power and higher specific impulse thruster systems. NASA continues to work closely with both supplier and user communities to maximize the understanding and acceptance of new technology in a timely and cost-effective manner. NASA's electric propulsion efforts are closely coordinated with Department of Defense and other national programs to assure the most effective use of available resources. Several NASA Centers are actively involved in these electric propulsion activities, including, the Glenn Research Center, Jet Propulsion Laboratory, Johnson Space Center, and Marshall Space Flight Center.
\end{abstract}

\section{INTRODUCTION}

NASA has a universe of destinations. The "easy" locations have been visited by fly-by science missions, orbiters, or landers. Spacecraft propulsion continues to be a significant performance driver to enable many mission destinations. To meet known and anticipated mission performance goals, in many instances advanced electric propulsion systems are required. To this end, NASA sponsors technology development projects to develop new electric propulsion systems for a wide variety of revolutionary space missions. The scope of the projects extends from low power systems for small spacecraft to very high power systems to support possible future human exploration. Strong emphasis on technology transfer continues with project efforts directed toward the development of commercial technology sources and the demonstration of project technologies to the level required by potential users. NASA projects are cross cutting and closely allied with other major national development efforts to ensure that a broad range of users are provided with new technologies in a timely and cost effective fashion. The NASA projects will continue to identify and develop new electric propulsion technologies and invites the participation of innovative members of the community in the coming years.

Activities in electric propulsion range from basic research through advanced development to flight demonstration. NASA is involved in projects with the Department of Defense, including the Air Force, Missile Defense Agency, Defense Advanced Research Projects Agency and the Navy. Transition of the technology to U.S. industry is a continuing effort. The unique capabilities of the NASA electric propulsion test-beds are being utilized by the U.S. satellite industry.

Projects are implemented by a combination of in-house activities, competitively procured contracts, open to NASA Centers, U.S. industry, and universities, and grants with universities. Industry involvement is designed to assure that commercial sources of new technologies are available and that all critical aspects of the technology, including both 
hardware development and spacecraft integration are addressed. This paper briefly describes major NASA electric propulsion activities.

\section{MISSIONS}

There is one active NASA satellite with Electric Propulsion at this time and one in development. In addition NASA is supporting a technology demonstration on an ESA spacecraft.

\section{EO-1}

NASA's Earth Observing-1 (EO-1) spacecraft continues to operate its pulsed plasma thruster successfully. The PPT has controlled the pitch of the spacecraft during operation of sensitive imaging sensors. Results have shown no adverse interaction between the PPT and the sensors or the rest of the spacecraft. The Goddard Space Flight Center manages and operates the spacecraft and was responsible for integration activities. NASA Glenn Research Center was responsible for the development of the PPT flight hardware. The Aerojet Redmond Rocket Center was responsible for the detailed design and hardware fabrication.

\section{DAWN}

The successful demonstration of the NSTAR Ion thruster on the DS-1 mission and the completion of the Extended Life Test have provided future mission planners with an "off-the-shelf" $2.3 \mathrm{~kW}$ ion thruster capable of processing greater than $120 \mathrm{~kg}$ of Xenon. The DAWN asteroid science mission is building a spacecraft with three NSTAR engines. JPL is managing the Boeing effort to build the ion propulsion system. This is the first NASA science mission to implement electric propulsion. Several "product improvements" are being incorporated into the engine as a result of the DS-1 experience and extended life test results.

\section{ST-7}

The Busek Company will provide a set of colloid thrusters for the ESA Smart2 spacecraft as part of the NASA New Millennium Program. The thrusters, part of the Disturbance Reduction System, are capable of controlling spacecraft position with extremely fine precision. Eight colloidal thrusters are mounted in clusters at four points on the spacecraft's perimeter. The thrusters generate enough thrust to control the spacecraft in the required six degrees of freedom. They will counteract both external and internal pressures on the test masses. The colloid thrusters will deliver throttleable thrust form 2 to 20 micro-Newtons. Smart2 is scheduled to fly in 2006.

\section{ENERGETICS PROJECT}

The Energetics Project has been the technology feeder project for NASA in the areas of advanced power and advanced propulsion. In FY05, it will be replaced by a set of projects that have been competed against Headquarters-selected technology focus areas. The Energetics project has been primarily performed at the Glenn Research Center with in-house activity, contracts and university grants. The tasks are directed toward understanding thrusters and thruster systems and bringing a level of technical maturity to new propulsion concepts.

A significant in-house propulsion activity - which takes advantage of the NASA GRC resident expertise, and unique electric propulsion infrastructure that has been established over the past 40 years - is maintained to address these development efforts. These in-house activities include the development of breadboard and engineering model thrusters and breadboard power processors. These activities establish design requirements and specifications that can then be transferred to NASA advanced development projects, flight projects or U.S. industry for flight application.

\section{Electrostatic-Ion}

The NASA Glenn Research Center (GRC) ion propulsion task addresses the need for high specific impulse (3000 10,000s) ion propulsion systems and technology across a broad range of mission applications and power levels. Development areas include: high-power - both high-throughput and high-specific impulse - engine components, engines, and power processing technology, lightweight high-efficiency sub-kilowatt ion propulsion, and fundamentals. 
The task includes a broad range of activities in the following areas: (1) Development of high-power ( 30-kW class) ion engine and component technologies applicable to Exploration-class and deep-space science missions; (2) Development of engine component technologies for NSTAR-derivative high-throughput ion engines, and highpower, modular, power processor units; (3) Development of lightweight sub-kilowatt ion propulsion system technology; and (4) Fundamentals - development of advanced diagnostics for life assessments, quantification of erosion processes, and development of new cathode technologies.

The primary objective of ion optics development is the validation of ion optics designs which yield a $>2 \mathrm{x}$ increase in life over that demonstrated with the Deep Space One ion engine optics technology. This included efforts in metallic (titanium) and carbon-based ion optics designs and continued technical support of Air Force CarbonCarbon (C-C) grid material contracts. Thirty-cm-diameter pyrolytic carbon ion optics have been fabricated geometrically identical to the molybdenum ion optics used on the NSTAR flight thruster. They were then installed on an NSTAR engineering model thruster and experimentally evaluated over the NSTAR operating envelope. All performance data compare favorably with data for the molybdenum flight ion optics. Subsequent to performance measurements, the pyrolytic carbon ion optics assembly was subjected to a vibration test. The thruster endured 9.3 grams of random vibration in the axial direction, similar to Deep Space-1 acceptance levels, and successfully passed vibration testing with no damage to the ion optics assembly.

A long-term objective of engine design optimization work has been to develop a sub-kilowatt ion engine suitable for mission opportunities identified for outer planetary exploration. Emphasis has been placed on identification of scaling parameters associated with plasma generation, and beam acceleration and neutralization functions, and optimization for low-power (100-500 W) operation. Efforts have been focused on the optimization of the discharge to eliminate plasma instabilities and improve electrical efficiencies. This included development of a thruster with variable length, magnetic circuit, and neutral injection schemes to establish experimental validation of discharge chamber plasma codes.

A JPL led team under an NRA contract from the Energetics Project has developed high Isp carbon/carbon grids. A set of carbon composite grids were recently tested at GRC. The testing used the GRC $76 \mathrm{~cm}$ diameter thruster body that had been previously built and characterized on $\mathrm{Xe}$ and $\mathrm{Kr}$ as part of the Code $\mathrm{R}$ Energetics project. Test results are not yet available.

Both the Energetics and the I-Space Technologies projects have been funding VACCO to develop an extremely small feed system that will be applicable to both ion and Hall systems. This advanced technology will significantly lighten future electric propulsion systems substantially by applying an entirely new approach to fluid control systems called Chemically Etched Miniature Systems or ChEMS(TM). The application focus is lightweight xenon feed system specifically designed for Ion or Hall thrusters for in-space propulsion.

Several additional Energetics research activities at GRC address base technologies. These elements include: 1) highly-efficient long-life cathodes and neutralizers; 2) improved thermal design; 3) improved magnetic circuit; 4) advanced power processing, 5) advanced grid materials; and 6) electrode-less plasma production. The effort has produced PPU stages with greater than 95 percent efficiency. Several of the evolving technologies could be incorporated into the next deep space mission to enhance performance and provide margin

In order to circumvent cathode lifetime issues particularly for high power thruster applications, a microwave thruster development task was initiated to assess and develop this technology for high power applications. Hollow cathode failure can occur after prolonged operation due to surface chemistry effects, and/or erosion due to ion bombardment. Ion thruster hollow cathodes are likely not suitable for applications requiring years of continuous operation.

Electrode-less schemes such as inductive and microwave driven discharges are potential replacement candidates. These schemes do not use cathodes and as a result, their lifetime is largely determined by the lifetime of the power supply or power tube. A microwave driven ECR source was selected as a design approach for high power. Characterization of a test-bed engine discharge was completed.

Measurements of sputter yields of Mo-Xe down to $50 \mathrm{eV}$ are being made, and measurements of the sputter etch rate of Ta-Xe and Mo-Xe at energies between 25 and $50 \mathrm{eV}$ are being made. These activities were conducted using a GRC low-energy sputtering rig, and a low-energy sputtering system with test samples immersed in a discharge chamber plasma. The objective of the activity is to develop a fundamental understanding of low energy sputtering 
processes, and to measure low energy sputtering etch rates of materials relevant to ion thrusters. The goal is to quantify the sputter etch rates of carbon and relevant refractory metals (including Ta, Ti, and Mo) under ion (Xe, and $\mathrm{Kr}$ ) bombardment, down to the threshold energies. This activity was conducted using the GRC low-energy sputtering rig, supported by a graduate student from Virginia Polytechnic Institute and State University.

\section{Electrostatic-Hall}

Hall effect thrusters offer many advantages including an attractive combination of high specific impulse (as compared to chemical thrusters) and high thrust-to-power ratio (as compared to ion thrusters). The net result is a fuel-efficient transfer with a reasonable trip time. Orbital applications such as space tugs, spacecraft orbit insertion, etc. could benefit from higher thrust systems to reduce trip time. Deep space, large delta V, missions typically require higher specific impulse to reduce fuel loading at the expense of trip time. Power rich spacecraft architectures provide an opportunity to take advantage of propulsion systems that provide both high power and high specific impulse. As allowable mass is allowed to increase for a mission, the optimum specific impulse tends to decrease and trip time shortens. The application of Hall thrusters to these missions requires substantial technology advancements from state-of-the-art thrusters.

A cooperative agreement with MIT for Hall thruster modeling is providing a theoretical understanding of the physical processes occurring in a Hall thruster and provides a better basis for design and scaling.

The technical content of the NASA's FY04 Hall thruster project, consists of five technical areas that support the objective of discovering mission enabling and enhancing Hall thruster concepts for NASA primary and secondary propulsion applications. The technical focus areas are as follows: High Specific Impulse, High-Power, High Efficiency, High Thrust, and Hall Thruster Lifetime.

\section{High Specific Impulse:}

The use of krypton as a propellant for electric propulsion devices is attractive for missions requiring both highspecific impulse and high-propellant throughput. The ionization efficiency of krypton in a thruster designed for xenon is decreased because the channel geometry and magnetic field are inappropriate. While the NASA-457M was designed for xenon, a performance evaluation of the thruster on krypton showed that the particular qualities of the channel and magnetic field (both of which have departed from typical xenon thruster designs) resulted in krypton efficiencies that were only slightly reduced from operation on xenon. These results, in conjunction with the results of previous Energetics sponsored low power krypton Hall thruster investigations, have provided the insight necessary to design a high-efficiency Krypton Hall thruster. Investigations of the NASA-173M added to the database of krypton Hall thruster performance. A medium power thruster was designed for krypton. The krypton performance and plasma properties of the NASA-173M were investigated as a function of channel length and magnetic field, with the goal of identifying an optimum choice based on propellant. Combined with the design of the NASA-457M, results of these experiments have been used to design a mid-power krypton Hall thruster.

\section{High Power:}

The success of the NASA-457M has demonstrated that a conventional Hall thruster can be made to operate efficiently with a discharge chamber width in excess of $6 \mathrm{~cm}$. A low risk approach to demonstrating Hall thruster technology at power levels up to $500 \mathrm{~kW}$ is to utilize the demonstrated discharge chamber cross sectional dimensions and magnetic field topology from the NASA-457M thruster in a larger thruster. By increasing the thruster diameter while maintaining the 457's channel cross section, a 2 meter outside diameter discharge chamber would be required for a $500 \mathrm{~kW}$ thruster designed to operate at a discharge current of 500 Amperes and a discharge voltage of 1000 Volts. A conceptual design for such a thruster has been completed. Issues include, but are not limited to: segmented discharge chamber design, segmented magnetic circuit design, and thermal expansion. This activity is currently on hold pending a further definition of the Code T needs.

\section{High Efficiency:}

Beginning in PY00 NASA Glenn Research Center began investigating Hall thruster performance outside the stateof-the-art performance envelope (1-5 kW, 1500-1800 seconds). Initially, the operation of Russian TAL and SPT thrusters were investigated at high current density and high discharge voltage. The efficiency of these thrusters increased with discharge voltage to a maximum efficiency, which occurred between 600-800 Volts. As discharge voltage was increased beyond this threshold, the thruster efficiency continued to decrease. During PY01-03, an element of NASA's Hall thruster project was focused on understanding the physical processes responsible for the 
maximum in thruster efficiency and minimizing this effect. These efforts resulted in a moderate power Hall thruster (NASA-173M v.2), which exhibits a linear relationship between efficiency and discharge voltage up to 1000 Volts.

The NASA-173M v.2 design effort focused on the magnetic circuit, which was tailored for efficient high voltage operation. While efficient Hall thruster operation was demonstrated at specific impulses greater than 3000 seconds, operation at high power density may be limited by the thermal design of the device. Performance was measured at power levels from 1.3 to $9.3 \mathrm{~kW}$, but a thermally steady-state condition was not demonstrated at elevated power levels. The implications of high power density Hall thruster operation have been investigated. Thruster component temperatures have been measured for a range of input power levels. A thermal model of the NASA-173M v.2 Hall thruster has also been developed. The thermal model results will be used as input for a structural model (thermal growth interference) to guide future, higher TRL level Hall thruster development. Because the magnetic circuit components are negatively affected by high power density operation, high temperature magnetic circuit design improvements have been considered.

\section{High Thrust:}

A thruster technology currently does not exist that bridges the gap in specific impulse between arcjets (500 s) and Hall thrusters (1600 s). High-thrust Hall thrusters operating between 1000-1200 s specific impulse could replace chemical thrusters by allowing rapid orbit insertion of Earth satellites or rapid planetary escape/capture trajectories for massive interplanetary robotic and piloted missions. The challenge of designing low-voltage Hall thrusters is the decrease in efficiency caused by diminished propellant utilization. Investigations of the NASA-457M have shown that anode efficiencies of 40 percent are possible around $1000 \mathrm{~s}$ specific impulse at nominal current densities. Propellant utilization has been substantially improved at low-voltage by increasing the current density by a factor of two or three from nominal. Control of the magnetic field topography has also been studied. The NASA-173M has been operated at low-voltage and high-current density to identify the design features necessary to enable efficient (50 percent), low-voltage/high-thrust Hall thrusters.

\section{Long Lifetime:}

The application of Hall thrusters has been historically limited to on-orbit maneuvers such as orbit-raising and station keeping. For these applications, the 8000 to 10,000 hour lifetime of moderate power (1.5-5.0 kW) Hall thrusters is sufficient. However, recent investigations have demonstrated that by using innovative magnetic circuit topography, efficient Hall thruster operation is achievable at high specific impulse ( $>3000$ seconds using xenon). For highpower Hall thrusters, specific impulses up to 4500 seconds have been demonstrated using krypton propellant. While the higher specific impulse makes the Hall thruster an attractive option for primary propulsion applications, lifetime in excess of 8000 hours is required.

The present life limiting mechanism of Hall thrusters is the erosion of the discharge chamber in which the plasma is ionized and accelerated. This erosion is attributed to ion bombardment of the chamber by energetic particles. After sufficient erosion has occurred at the exit plane of the device, the magnetic pole pieces are exposed to ion bombardment. While Hall thrusters have been shown to operate with the pole pieces exposed to the plasma, erosion of the magnetic circuit elements alter the magnetic topography and change the thruster's operational characteristics. As a result, end of life has been defined as the point when sufficient discharge chamber erosion has occurred to expose the magnetic circuit elements.

A significant effort has been made to understand the governing mechanisms of the erosion processes. Analytic tools, which describe the erosion processes, have been developed. The ion trajectory and flux to the walls has been studied. Various approaches have also been employed to increase Hall thruster lifetime by using chamber materials with lower sputter yield, increasing the radial thickness of the channel, controlling the plasma magnetically, and attempts to move the ion acceleration outside of the thruster exit plane. These investments have not yielded the $5 \mathrm{X}$ increase in Hall thruster lifetime that is desirable.

A concept has been developed that can refresh the channel material. As the discharge channel erodes, the boron nitride channel will be extended providing the required protection of the magnetic components. The requirements of the extendable ceramic thruster concept have been determined. Mechanical concepts for discharge channel actuation have been identified and evaluated in terms of required mechanical characteristics, reliability and environmental suitability. 


\section{Electromagnetic-PPT}

Pulsed plasma thrusters (PPTs) have potential for application to a range of spacecraft control functions, including attitude control and translation propulsion, momentum management, drag make-up, orbit raising, and large space structure dynamic control. PPTs have seen limited use in drag make-up and attitude control functions. The objective of this component of the Energetics project is to advance the PPT state-of-art to effect routine PPT placement in spacecraft control systems. Three technology goals are lightweight multi-thruster PPT systems, highefficiency single-axis PPT systems, and a better understanding of PPT physics. Flying the PPT on the EO-1 spacecraft pointed to several improvements. PPT-specific systems analysis is performed to continually upgrade our understanding of the technology drivers.

The lightweight PPT system would consist of a centralized power processing unit (PPU) driving 4 to 6 thruster modules, each with 1 to 3 throttleable thrust axes. Such a system could provide attitude control and translation maneuvers at selectable thrust, total impulse and impulse bit levels. Performance targets include $15 \mathrm{~kg}$ system mass, 95 percent impulse bit accuracy, and a life of over 50M pulses.

Application of PPTs to orbit raising/drag make-up functions is currently limited by the low efficiencies of SOA PPTs, resulting in inadequate thrust at low power levels. The high efficiency PPT technology goal focuses on increasing the efficiencies of a single axis PPT, while extending life to support longer duration missions. The performance target is to double the efficiency to 20 percent and raise the thrust to about $4 \mathrm{mN}$ while maintaining long life and light weight.

The fundamental research effort is developing a Pulsed Plasma Thruster with thrust efficiency greater than 20 percent with a specific impulse greater than $1500 \mathrm{sec}$. This research effort focuses on accomplishing the higher performance goals by researching a new thruster configurations, new discharge current waveforms, and evaluating parallel-rail thrust performance at higher capacitor energies. In addition, time-resolved temperature measurements in the propellant solid will be compared with numerical simulations from state-of-the-art numerical models for propellant ablation to provide insights into the means of improving thruster performance by maximizing propellant utilization.

\section{Electromagnetic-MPD}

The Energetics MPD thruster task is investigating and improving the performance of high power MPD thrusters through numerical simulations, pulsed MW-class experiments, and 100-kW class steady-state thruster experiments. The primary objective of this research is to achieve thrust efficiencies exceeding 50 percent with non-condensable gas propellants, while operating the thruster below the threshold for plasma instabilities. A pulsed experimental facility provides sufficient power and pulse duration to form and accelerate a quasi-steady MW-class MPD plasma that mimics the performance of a steady-state plasma thruster. The terminal voltage of a pulsed device will be slightly higher, and the electrothermal thrust component somewhat lower, than a steady-state device, hence the total measured efficiency will be slightly less than the efficiency achieved by a steady-state thruster operating under equivalent power and mass flow conditions. These effects are expected to lessen with increasing power levels. However, electrode heating and material erosion cannot directly be addressed using the quasi-steady facility. To investigate the performance and lifetime of steady-state devices, a 100-kW class thruster test facility is being constructed and installed in facilities at the Glenn Research Center. The complementary capabilities provided by the pulsed and steady-state facilities will provide a unique, world-class ability to develop MPD thruster systems for near-term sub-MW applications as well as potential future power rich MW-class piloted and robotic exploration missions.

Performance testing of high power self-field MPD thrusters continues with the goal of achieving higher thrust efficiency using non-condensable gas propellants. Activities include operation with argon and hydrogen at power levels up to 5-MW. This work is performed in conjunction with numerical modeling to develop efficient MW-class MPD thrusters with electrode geometries suitable for future steady state, long life operation. Both self-field and applied-field thruster operation have been investigated.

The MACH2 code is being used at the Arizona State University to model the performance of high power self-field and sub-MW applied-field MPD thrusters. The code successfully models thrust and plasma voltage for various thruster geometries and propellants over a wide power range, and was used in FY02 to design a self-field nozzleanode MPD thruster with a predicted efficiency of approximately 50 percent. The model is being extended to 
MW-class applied-field MPD thrusters to investigate potential mechanisms for additional thrust enhancement using applied magnetic fields.

A system-level model has been developed to predict the thermal management requirements, engine specific mass, etc. for MW-class MPD thrusters operated with various propellants. This model has been extended to applied-field MPD thrusters and validated using published experimental performance data. The goal of the system modeling effort is to provide mission planners with a quick look MPD thruster simulation tool when considering propulsion options for various mission scenarios.

\section{Systems}

The Systems task is developing power processing and propellant management technologies and assessing spacecraft integration issues for all electric thrusters at any power level. Every electric propulsion (EP) system requires a power processing unit (PPU) that in most historical cases, if not all, has been the most complex, massive, and/or expensive sub-system. PPUs not only have to meet all the thruster power and control requirements but also spacecraft (power, control, radiation, EMI, thermal, etc.) requirements.

Previously, testing of a multi-kilowatt power module was conducted. Efficiencies in excess of 95 percent were measured. Various significant improvements were identified. These have been implemented into the design to increase efficiency. Most consist of "repackaging" the breadboard to allow better cooling of the power components. However, alternate architectures and components have been implemented also.

A 3-kW modular discharge supply has been integrated with a Hall thruster to validate current sharing with an active plasma load during turn-on and steady state operation.

Hall thruster plasma discharges are unstable and oscillatory. These oscillations can potentially induce instabilities in the discharge power supply leading to failure. Oscillations impact PPU design issues including filter design, switching frequency selection, and loop response. Traditionally, a matching network consisting of an L-C filter has been used to mitigate effects of oscillations in the discharge supply. Optimization of this matching network is necessary to minimize PPU mass and maximize efficiency. Experiments were conducted to measure the impedance of the plasma discharge using the NASA-120M Hall thruster. The data obtained shows some characteristics of the plasma discharge impedance. Measurements obtained so far show that the discharge plasma load characteristic is primarily capacitive, as references have suggested. Impedance measurements are continuing using a high-power frequency response analyzer to understand Hall thruster load characteristics. In addition, the output impedance of various laboratory power supplies and breadboard discharge supplies have been measured to understand source-load interactions.

The Energetics project has been funding VACCO to develop an extremely small feed system that will be applicable to both ion and Hall systems. The project significantly lightens future electric propulsion feed systems by applying an entirely new approach to fluid control systems called Chemically Etched Miniature Systems or ChEMS(TM). The application focus is lightweight xenon feed system specifically designed for Ion or Hall thrusters for in-space propulsion. The "credit card" sized feed system has been successfully tested with a Hall thruster.

\section{Studies}

The NASA Energetics EP project has a deep commitment to mission and technology trade studies. These studies guide the directions of the technology project so that every technology effort can be tied to a potential future use and that the potential benefits are understood. Innovative studies of low thrust trajectories for missions to outer solar system bodies have resulted in time saving options for fly-by and orbiting spacecraft. The Energetics project has also been tasked to assess the viability and architectures associated with nuclear propulsion for large telescopes at the Earth-Sun L2 Lagrange point.

\section{Feed Systems}

The VACCO CHeMs feed system has been integrated and tested with a Hall thruster. 


\section{Other High Power}

The Energetics Project has provided support for development of the advanced VASIMR concept. The VASIMR system is a high power, plasma rocket that is capable of exhaust modulation at constant power. It consists of three major magnetic cells where plasma is respectively injected, heated and expanded through a magnetic nozzle. During VASIMR operation, neutral gas is injected at the forward cell and ionized. The resulting plasma is heated with RF energy in the central cell to the desired temperature and density, by the process of ion cyclotron resonance. After heating, the plasma is magnetically (and gas-dynamically) exhausted at the aft cell to provide modulated thrust. The VASIMR concept is designed to evolve to power levels up to $100 \mathrm{MW}$. To date, thrust measurements have been inferred from other experimental data.

\section{IN-SPACE PROPULSION PROGRAM}

The coming generation of scientific exploration missions presents a unique set of challenges. Chief among these is the ability to rendezvous with, orbit, and conduct in situ exploration of the planets, satellites, and small bodies. The purpose of In-Space Program is to develop in-space propulsion technologies that can benefit near- to mid-term NASA science missions by significantly reducing travel times required for transit to distant bodies. The In-Space Propulsion Program is charged to produce and manage a propulsion technology development plan which will mature technologies into flight mission designs within three to five years of initiation, and will result in a factor of two reduction in planetary travel times in 10 years. Flight demonstration is not part of the program.

\section{NEXT}

While the NSTAR thruster is appropriate in terms of power level and lifetime for some Discovery Class missions, its application to larger Discovery and New Horizons missions is limited due its power and total impulse capability. NEXT offers a solution to take spacecraft to places in the solar system that are of scientific interest to the science community.

An In-Space NRA process selected a GRC led team to develop a next generation throttleable $\sim 7 \mathrm{~kW}$ ion thruster capable of processing $>400 \mathrm{~kg}$ of Xenon (NEXT). The project addresses the entire ion propulsion system, including the engine, the gimbal, the PPU, the feed system, and total system integration. The development is taking full advantage of the experience gained by developing and flying the NSTAR engine. Even at the $7 \mathrm{~kW}$ level, clustering of engines may be necessary to attain the total thrust and total impulse necessary for ambitious missions. The NEXT project will revisit the clustering work performed at Glenn in the 80's and demonstrate operation with a cluster of three engines. A 2000 hour wear test has been completed. The thruster has successfully completed a vibration test. The GRC built thruster, with a breadboard PPU from Boeing and a breadboard feed system from Aerojet completed a system integration and performance test.

NEXT is also conducting many fundamental investigations of the associated propulsion system components and thruster internal diagnostics. The NEXT PPU beam supply has demonstrated $>96$ percent efficiency.

The NEXT project has started its second phase of development. The NEXT technology will be matured to TRL 6 by operating a prototype system test. Critical components will be tested to qualification levels of performance.

The thruster is being prepared to start an 8-10,000 life test to demonstrate life by processing at least $185 \mathrm{~kg}$ of Xenon.

VACCO has recently been selected in the In-Space NRA to demonstrate the ChEMS feed system with the NEXT thruster.

\section{CBIO}

The same NRA mentioned above selected Boeing Electron Dynamics Division to develop carbon based grids for high power, high Isp engine systems such as NEXT. BEDD is leading a team in the development of advanced

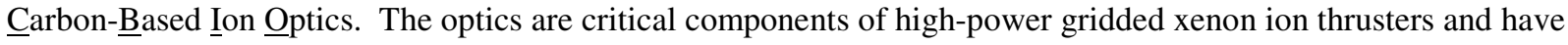
limited lifetime. Current activities are developing and testing 30cm pyrolytic graphite and carbon/carbon optics. The task should result in the development of carbon based ion optics applicable to the $40 \mathrm{~cm}$ NEXT thruster. The 
CBIO project also includes the development and validation of an Ion Optics Lifetime Computer Model to predict the performance and lifetime of candidate grid designs.

\section{NSTAR Post-Life-Test Analysis}

The NSTAR extended life test was been terminated after $>30,300$ hours of operation at a variety of throttle settings. The engine is being disassembled and dissected to learn as much as possible about life limiting mechanisms. In spite of considerable erosion of some components, the engine had been operating normally at shut down.

\section{High Power Hall}

The In-Space Program tasked GRC to advance the TRL of the existing, laboratory model NASA-457M Hall thruster (TRL 3-4) by addressing the thermal, mechanical and structural issues. This will allow steady state operation at or above the $50 \mathrm{~kW}$ level. During earlier testing, the device was limited by thermal expansion of components and was, by design, heavy. The task includes modifying the design of components, including the magnets, with respect to their thermal performance. The modifications will improve thermal conduction of internally generated heat so as to allow continuous steady state thermal operation at or above the $50 \mathrm{~kW}$ power level. Modifications will also result in a 20 percent mass reduction. This reduction in thruster mass will be obtained by optimizing the magnetic circuit with respect to mass and removing iron from the magnetic circuit and support frame. Design and fabrication of a longer live high current hollow cathode is also part of the task. Performance of the thruster is not expected to be unaffected.

\section{HIVHAC}

Detailed mission analysis has demonstrated that using on-board power and a 6-8 kilowatt, 2200-2800 second specific impulse Hall thruster during both Earth orbital and interplanetary phases of a mission results in a launch vehicle step down, a reduction in total trip time, or an increase in maximum delivered payload. This multi-year activity will address high Isp, low specific mass and high system efficiency. Full advantage will be taken of the successful experience gained in the design of NASA-173 high voltage Hall thruster in the Energetics project. The $\underline{H i g h} \underline{\text { Voltage }}$ Hall $\underline{\mathrm{AC}}$ celerator thruster system will be targeted at the 6-8 kW, 2200-2800s performance level. The thruster, conceived to have low specific mass and a robust mechanical design, will be evaluated by analysis and test with respect to performance, thermal behavior, and lifetime. The design will be evolvable to flight quality.

\section{PROJECT PROMETHEUS}

NASA's Project Prometheus has begun efforts to develop electric propulsion technologies that can take advantage of space nuclear power systems. The mission attributes enabled by the combination of space nuclear power and electric propulsion technologies include more sophisticated active/passive remote sensing, greater launch window flexibility and spacecraft maneuverability at the target planet or moon, and greatly increased science data rates. The mission set is focused on a proposed $100 \mathrm{kWe}$ nuclear electric powered flagship science mission, but other electric propulsion systems for challenging exploration missions are also being examined.

The electric propulsion technologies of interest and under development include high power/high $\mathrm{I}_{\mathrm{sp}}$ gridded ion and Hall thrusters. Base technology developments, such as long life components, electrodeless concepts, and alternate propellants are also being explored. These efforts will contribute to several of the aforementioned propulsion technologies.

Electric propulsion technology efforts are organized in two main areas for Project Prometheus: multi-mission technologies and advanced technologies. Multi-mission technologies are those that will enable a new class of exploration robotic missions not possible with current space propulsion and power systems and that would support the first proposed mission identified to use these nuclear electric propulsion (NEP) technologies: the Jupiter Icy

Moons Orbiter (JIMO) mission. NEP technologies directly related to enabling this first flight mission include high power/high $\mathrm{I}_{\mathrm{sp}}$ gridded ion propulsion system concepts, long life components, modeling, high voltage insulators, high power PPU options, and radiation hardened components and materials. The advanced technologies development activities would focus on advanced, large-scale space nuclear propulsion technologies that would enable more advanced, ambitious missions (both robotic and human) not possible with the multi-mission technologies being developed for the first NEP flight applications. 


\section{Multi-Mission Electric Propulsion Technologies}

\section{JIMO}

Independent government and industry teams are still studying specific requirements for the JIMO mission. However, some top level technology needs for the propulsion system have been identified: (1) High Power: $10 \mathrm{~kW}$ to $50 \mathrm{~kW}$ per thruster; (2) High $\mathrm{I}_{\mathrm{sp}}$ : $2000 \mathrm{sec}$ to $9000 \mathrm{sec}$; (3) Long Life: A propulsion system capable of 5 to 10 years burn time; and (4) Radiation Tolerance: The Jupiter environment will require very radiation resistant materials.

\section{HiPEP/NEXIS}

The HIPEP and NEXIS projects were selected through an NRA competition to provide technology and engine systems. Preliminary design requirements for the NRA call for $>20 \mathrm{~kW},>6000-8000$ s, longer life engine systems to enable high power robotic missions as presently designed.

HIPEP, awarded to a GRC led team, is to demonstrate a $~ 8000 \mathrm{~s}, 25 \mathrm{~kW}$ engine system. The design concept includes a microwave cathode and neutralizer and a rectangular geometry that is thought to be more scalable than a cylindrical engine. DC operation is a backup option. The NRA's technical requirements relating to power, Isp, and efficiency have been demonstrated. The primary technical challenge of the ion thruster is lifetime. HIPEP is addressing this with microwave propellant ionization in the discharge chamber and neutralizer, and newly designed pyrolytic graphite high-voltage ion optics.

The NEXIS project, awarded to a JPL led team, is concentrating on a $7500 \mathrm{~s}, 20 \mathrm{~kW}$ engine system with focus on improving life limiting components by investigating cathode/neutralizer improvements and carbon composite grids. The NEXIS technology represents an improvement in the state-of-the-art cylindrical designs and is intended to eliminate known thruster wear-out failure modes while increasing the thruster power to $20 \mathrm{~kW}$ and Isp to $7500 \mathrm{~s}$. The NEXIS technology uses erosion resistant carbon-carbon grids, a new reservoir hollow cathode, a 65-cm diameter chamber masked to produce a $57-\mathrm{cm}$ diameter ion beam, and shared neutralizer architecture to achieve very high propellant throughput capability and an efficiency of $\sim 78$ percent.

Both HiPEP and NEXIS are conducting many fundamental investigations of the associated propulsion system components and thruster internal diagnostics that can then be applied to the proposed JIMO mission.

\section{Advanced Electric Propulsion Technologies}

\section{High Power Hall}

High power Hall thruster propulsion has been shown to be a potentially enabling technology for various applications including piloted Mars missions, a space solar power concept and missions that could involve destinations such as libration points. Of particular near-term interest would be to possibly use Hall based propulsion as an assisting technology in conjunction with conventional gridded ion systems for NEP missions to distant solar system destinations. The high power, high $\mathrm{I}_{\mathrm{sp}}$ Hall thruster could enable robotic science missions requiring $\mathrm{I}_{\mathrm{sp}} \mathrm{s}$ in the $5000 \mathrm{~s}$ to 6000s range. This GRC-led high power Hall effort conducts research on the high power technologies for midterm robotic science missions (requiring mid-range $\mathrm{I}_{\mathrm{sp}} \mathrm{s}>4000 \mathrm{sec}$ ) as well as far term fast piloted missions (requiring lower $\mathrm{I}_{\mathrm{sp}} \mathrm{s} 2000 \mathrm{~s}-5000 \mathrm{~s}$ ). The potential use of nuclear fission reactors for space applications provides further impetus for investigating the development of 50-100 kW class Hall based propulsion systems.

The development and evaluation of a new high power Hall thruster, beyond the NASA-457M, optimized for operation at high specific impulse, and applicable to mission strategies being considered for Project Prometheus, is being pursued.

The effort consists of technology development and evaluation tasks. Under the technology development task, a new thruster, designated the NASA-400, based on the NASA-457M has been designed for operation at higher $\mathrm{I}_{\mathrm{sp}} \mathrm{s}$. The thruster has incorporated improved electrical isolation and discharge channel modifications to achieve high voltage operation at the desired power level. The redesigned thruster has been fabricated and a performance investigation conducted under the evaluation task. The availability of large billets of ceramic has facilitated the design and construction of the thruster. 


\title{
Advanced Electric Propulsion Technologies NRA
}

NASA has announced several research and technology development NRAs in the area of advanced electric propulsion (EP) that now supports the NASA exploration mission objectives. Multiple awards for these NRA solicitations are expected to be announced in FY04. The research is targeted at EP thrusters that process in excess of $100 \mathrm{~kW}$ of power at $\mathrm{I}_{\mathrm{sp}}$ in excess of 5000 seconds.

\section{Critical Issues in Electric Propulsion}

The Critical Issues in Electric Propulsion NRA has solicited for technologies that increase EP thruster lifetime in the range of 5-15 years, reduce thruster weight, facilitate power and specific impulse throttling, and seek alternative, more advantageous propellants.

\begin{abstract}
Advanced Electric Propulsion Thrusters Life Modeling
Ion thrusters demonstrated decades ago most of the performance, in terms of Isp, thrust, power and efficiency, required for future missions. The major issue facing advanced ion thruster implementation is thruster life. In the past, life assessment and assurance has been based on life tests, from which it is likely that the most probable failure mechanisms are known. Since proposed missions already approach or exceed our capability to life test thrusters, life assessment and validation can only be accomplished by using predictive wear models. The JIMO Life Modeling and Test task is aimed at developing the required physics-based models and validating the model predictions with laboratory testing of thruster components and short-term wear tests. Some of the required models are available and others are in development. For example, JPL's CEX-2D and CEX-3D ion optics codes have already demonstrated the ability to accurately predict grid wear and the onset of the primary failure mechanism in NSTAR Extended Life Test, and have successfully predicted the grid erosion patterns observed in the recent NEXT 2000 hour wear test. Detailed models of the cathode insert, keeper region, and discharge chamber, validated by laboratory experiments, are under development. Physics-based thruster modeling efforts such as these also provide thruster performance degradation information over the life of the thruster to aid in the mission planning and propellant budget. The LMT task will provide life predictions for each component of the thruster, and a model of the performance of the thruster versus time, for future missions that use advanced ion propulsion.
\end{abstract}

\section{OTHER RELATED ACTIVITIES}

\section{Electrostatic-Colloid}

In addition to the flight hardware development for the ST-7, fundamental technology activities are funded to understand the physics of colloid thrusters and variants. MIT is studying microstructures as a thruster array and JPL is studying the stability of propellant after exposure to radiation. Yale is studying a variant that uses an alternate process to create droplets. GSFC and the University of Washington are collaborating on a colloid thruster.

\section{Electromagnetic-Plasmoid Thruster}

MSFC, as part of an effort to identify new technologies for propulsion, is revisiting a decade old concept where low temperature ionized gases containing internal electric currents (called plasmoids) are formed and expanded down a diverging electrically conducting nozzle. During the expansion of the plasma both the inductive and thermal energies are converted to directed kinetic energy, producing thrust. Since most of the energy is inductive, losses due to dissociation and ionization are thought to be small. Specific impulses are predicted to be in the 5000 to $20000 \mathrm{~s}$ range with thrusts from 1.0 to $5000 \mathrm{~N}$, depending on available power. A wide variety of propellants appear possible. The high specific impulse is possible even with higher atomic number propellants. Because the possibility may exist to form these plasmoids inductively, electrodes can be eliminated, providing the long service life required for planetary missions. Current work is directed toward implementing liquid metal feed through porous cathode structures and developing thrust stands for "high thrust" pulsed devices.

\section{Electro-static-Ion}

JPL is continuing to pursue independent product improvements for $30 \mathrm{~cm}$ ion engines. Reported at this conference is work on plasma diagnostics and hollow cathode emitters. 


\section{CONCLUSION}

The current state of electric propulsion within NASA is strong. There are several projects underway for flight or precursor flight systems. Base technologies are being pursued that will lead to better implementation of known technologies. Some speculative research is being pursued in areas that may lead to future thruster systems. 
Public reporting burden for this collection of information is estimated to average 1 hour per response, including the time for reviewing instructions, searching existing data sources, gathering and maintaining the data needed, and completing and reviewing the collection of information. Send comments regarding this burden estimate or any other aspect of this collection of information, including suggestions for reducing this burden, to Washington Headquarters Services, Directorate for Information Operations and Reports, 1215 Jefferson Davis Highway, Suite 1204, Arlington, VA 22202-4302, and to the Office of Management and Budget, Paperwork Reduction Project (0704-0188), Washington, DC 20503.

\begin{tabular}{|l|l|l|}
\hline 1. AGENCY USE ONLY (Leave blank) & $\begin{array}{c}\text { 2. REPORT DATE } \\
\text { October } 2004\end{array}$ & $\begin{array}{r}\text { 3. REPORT TYPE AND DATES COVERED } \\
\text { Technical Memorandum }\end{array}$ \\
\hline
\end{tabular}

4. TITLE AND SUBTITLE 5. FUNDING NUMBERS

An Overview of Electric Propulsion Activities at NASA

6. AUTHOR(S)

John W. Dunning, Jr., John A. Hamley, Robert S. Jankovsky, and Steven R. Oleson

7. PERFORMING ORGANIZATION NAME(S) AND ADDRESS(ES)

National Aeronautics and Space Administration

John H. Glenn Research Center at Lewis Field

Cleveland, Ohio 44135-3191

WBS-22-699-10-01

9. SPONSORING/MONITORING AGENCY NAME(S) AND ADDRESS(ES)

National Aeronautics and Space Administration

Washington, DC 20546-0001

8. PERFORMING ORGANIZATION REPORT NUMBER

E-14790

10. SPONSORING/MONITORING AGENCY REPORT NUMBER

NASA TM-2004-213329

AIAA-2004-3328

\section{SUPPLEMENTARY NOTES}

Prepared for the 40th Joint Propulsion Conference and Exhibit cosponsored by the AIAA, ASME, SAE, and ASEE, Fort Lauderdale, Florida, July 11-14, 2004. Responsible person, John A. Hamley, organization code 6910, 216-977-7430.

12a. DISTRIBUTION/AVAILABILITY STATEMENT

12b. DISTRIBUTION CODE

Unclassified - Unlimited

Subject Category: 20

Distribution: Nonstandard

Available electronically at http://gltrs.grc.nasa.gov

This publication is available from the NASA Center for AeroSpace Information, 301-621-0390.

13. ABSTRACT (Maximum 200 words)

This paper provides an overview of NASA's activities in the area of electric propulsion with an emphasis on project directions, recent progress, and a view of future project directions. The goals of the electric propulsion programs are to develop key technologies to enable new and ambitious science missions and to transfer these technologies to industry. Activities include the development of gridded ion thruster technology, Hall thruster technology, pulsed plasma thruster technology, and very high power electric propulsion technology, as well as systems technology that supports practical implementation of these advanced concepts. The performance of clusters of ion and Hall thrusters is being revisited. Mission analyses, based on science requirements and preliminary mission specifications, guide the technology projects and introduce mission planners to new capabilities. Significant in-house activity, with strong industrial/academia participation via contracts and grants, is maintained to address these development efforts. NASA has initiated a program covering nuclear powered spacecraft that includes both reactor and radioisotope power sources. This has provided an impetus to investigate higher power and higher specific impulse thruster systems. NASA continues to work closely with both supplier and user communities to maximize the understanding and acceptance of new technology in a timely and cost-effective manner. NASA's electric propulsion efforts are closely coordinated with Department of Defense and other national programs to assure the most effective use of available resources. Several NASA Centers are actively involved in these electric propulsion activities, including, the Glenn Research Center, Jet Propulsion Laboratory, Johnson Space Center, and Marshall Space Flight Center.

14. SUBJECT TERMS

Electric propulsion

\begin{tabular}{|c|c|c|}
\hline $\begin{array}{c}\text { 17. SECURITY CLASSIFICATION } \\
\text { OF REPORT } \\
\text { Unclassified }\end{array}$ & $\begin{array}{c}\text { 18. SECURITY CLASSIFICATION } \\
\text { OF THIS PAGE } \\
\text { Unclassified }\end{array}$ & $\begin{array}{c}\text { 19. SECURITY CLASSIFICATION } \\
\text { OF ABSTRACT } \\
\text { Unclassified }\end{array}$ \\
\hline
\end{tabular}

NSN 7540-01-280-5500

Standard Form 298 (Rev. 2-89)

Prescribed by ANSI Std. Z39-18 298-102 

